\title{
OHVIRA and OSVIRA syndrome
}

Sir,

I read with great interest the article titled, "Herlyn-Werner-Wunderlich syndrome presenting with infertility: Role of MRI in diagnosis" by Ahmad et al. in Indian Journal of Radiology and Imaging. ${ }^{[1]}$ The manuscript is informative. However, I would like to make the following contributions.

OHVIRA, also known as Herlyn-Werner-Wunderlich syndrome, abbreviates a complex urogenital anomaly whose embryopathogenesis is still putative. It reads out as Obstructed HemiVagina and Ipsilateral Renal Agenesis/Anomaly. ${ }^{[1]}$ Besides, it has a didelphic uterus. ${ }^{[1]}$ Central to understanding of the pathology is embryogenesis of vagina, a disputed topic as yet. While classically the upper vagina is believed to have Mullerian (paramesonephric) roots akin to fallopian tubes, uterus and cervix with sinovaginal bulbs forming the remainder of the lower vagina, recent studies debunk this age-old concept. ${ }^{[2]}$ Acien ${ }^{[2]}$ proposed Wolffian (mesonephric) origin of vagina in entirety - a notion which has been proved in experiments on female rats by Sanchez. ${ }^{[3]}$

Using Acien's hypothesis, all three components of OHVIRA can be fully explained. ${ }^{[2]} \mathrm{A}$ faulty development of mesonephric duct fails to induce the metanephric blastema, the future kidney. Also because vagina is Wolffian in origin, it too does not develop. Further, lack of growth factors from the mesonephros disturbs the proper positioning and placement of the paired paramesonephric ducts, resulting in nonfusion (uterus didelphys). Hence, the result is OHVIRA syndrome. ${ }^{[2]}$
On a parallel track is a constellation of urogenital anomalies in males grouped under the so-called Zinner syndrome (ZS). It comprises atresia of unilateral ejaculatory duct that leads to obstruction and dilation of seminal vesicle (seminal vesicle cyst) with ipsilateral renal agenesis. ${ }^{[4]}$ Because all the components of this syndrome are mesonephric in origin, Aswani et al. postulated similar embryopathogenesis of ZS in males as that of OHVIRA in females (as per new hypothesis of Wolffian origin of vagina). ${ }^{[5]}$ This concept thus places ZS as a male equivalent of OHVIRA, unlike previously where ZS was thought to be a male counterpart of Mayer-Rokitansky-Küster-Hauser (MRKH) syndrome in females. ${ }^{[6]}$ The caveat here is that MRKH is a Mullerian anomaly, while ZS is Wolffian in origin. ${ }^{[5]}$ Finally, Aswani et al. proposed OSVIRA as an acronym for ZS, similar to its female equivalent OHVIRA, which expands as Obstructed Seminal Vesicle and Ipsilateral Renal Agenesis. ${ }^{[5]}$

Financial support and sponsorship

Nil.

\section{Conflicts of interest}

There are no conflicts of interest.

Raj Bharatkumar Koticha

Department of Radiology, HBT Medical College and RN Cooper Hospital, Vile Parle West, Mumbai, Maharashtra, India E-mail: rkoticha@gmail.com

\section{References}

1. Ahmad Z, Goyal A, Das CJ, Deka D, Sharma R. Herlyn-Werner-Wunderlich syndrome presenting with infertility: Role of MRI in diagnosis. Indian J Radiol Imaging 2013;23:243-6. 
2. Acién P. Embryological observations on the female genital tract. Hum Reprod 1992;7:437-45.

3. Sánchez-Ferrer ML, Acién MI, Sánchez del Campo F, Mayol-Belda MJ, Acién P. Experimental contributions to the study of the embryology of the vagina. Hum Reprod 2006;21:1623-8.

4. Kanavaki A, Vidal I, Merlini L, Hanquinet S. Congenital seminal vesicle cyst and ipsilateral renal agenesis (Zinner syndrome): A rare association and its evolution from early childhood to adolescence. European J Pediatr Surg Rep 2015;3:98-102.

5. Aswani Y, Varma R, Choudhary P, Gupta RB. Wolffian origin of vagina unfolds the embryopathogenesis of OHVIRA (Obstructed Hemivagina and Ipsilateral Renal Anomaly) syndrome and places OHVIRA as a female counterpart of Zinner syndrome in males. Pol J Radiol 2016;81:549-56.

6. Ghonge NP, Aggarwal B, Sahu AK. Zinner syndrome: A unique triad of mesonephric duct abnormalities as an unusual cause of urinary symptoms in late adolescence. Indian J Urol 2010;26:444-7.
This is an open access journal, and articles are distributed under the terms of the Creative Commons Attribution-NonCommercial-ShareAlike 4.0 License, which allows others to remix, tweak, and build upon the work non-commercially, as long as appropriate credit is given and the new creations are licensed under the identical terms.

\begin{tabular}{|l|l|}
\hline \multicolumn{2}{|c|}{ Access this article online } \\
\hline Quick Response Code: & \\
\hline & Website: \\
\hline & www.ijri.org \\
\cline { 2 - 2 } & \\
& \\
&
\end{tabular}

Cite this article as: Koticha RB. OHVIRA and OSVIRA syndrome. Indian J Radiol Imaging 2018;28:375-6.

๑) 2018 Indian Journal of Radiology and Imaging | Published by Wolters Kluwer - Medknow 